\title{
Detailed information about chemotherapy in breast control arm might affect cognitive sequelae compared with endocrine therapy patients
}

\author{
Kadri Altundag $^{1}$ (i) \\ Received: 6 January 2018 / Accepted: 13 January 2018 / Published online: 20 January 2018 \\ ○) Springer Science+Business Media, LLC, part of Springer Nature 2018
}

To the Editor,

I wish to congratulate Underwood and colleagues for their review article [1] in which they presented a meta-analysis related to cognitive sequelae of endocrine therapy in women treated for breast cancer. They reported that verbal learning/ memory was the only domain where endocrine therapy (ET) patients performed worse than both non-cancer and breast cancer (BC) controls. As far as I understand from Methods section, ET patients received only endocrine treatment. However, detailed information regarding whether patients received chemotherapy or not and if received how long and which schedules they received chemotherapy in BC control arm were not described. These factors might also affect cognitive sequelae of patients in $\mathrm{BC}$ control arm and should be taken into consideration when compared with ET patients [2].

\section{Compliance with ethical standards}

Conflict of interest I have no conflict of interest to declare.

\section{References}

1. Underwood EA, Rochon PA, Moineddin R, Lee PE, Wu W, Pritchard KI, Tierney MC (2017) Cognitive sequelae of endocrine therapy in women treated for breast cancer: a meta-analysis. Breast Cancer Res Treat. https://doi.org/10.1007/s10549-0174627-4

2. Cerulla N, Arcusa À, Navarro JB, Garolera M, Enero C, Chico G, Fernández-Morales L (2017) Role of taxanes in chemotherapyrelated cognitive impairment: a prospective longitudinal study. Breast Cancer Res Treat 164(1):179-187. https://doi.org/10.1007 /s10549-017-4240-6
Kadri Altundag

altundag66@yahoo.com

1 MKA Breast Cancer Clinic, Tepe Prime, Cankaya, 06800 Ankara, Turkey 